\title{
Property and Cost Optimisation of Novel UHS Stainless Steels via a Genetic Alloy Design Approach
}

\author{
Wei $X U^{1,2)}$ and Sybrand van $\operatorname{der}$ ZWAAG $^{1)}$ \\ 1) Novel Aerospace Materials, Faculty of Aerospace Engineering, Delft University of Technology, Kluyverweg 1, 2629 HS, Delft, \\ The Netherlands. $\quad$ 2) ArcelorMittal Globle R\&D Gent, J.F. Kennedylaan 3, 9060, Zelzate, Belgium.
}

(Received on October 13, 2010; accepted on March 15, 2011)

\begin{abstract}
A computational alloy design approach for precipitation harden Ultra High Strength (UHS) stainless steels is presented. The design methodology is based on thermodynamic and kinetic principles, employing genetic algorithm for optimization. Alloy compositions covering 14 elements are optimized simultaneously together with key heat treatment parameters, i.e., austenitization temperature and ageing temperature, so as to achieve the desired microstructures: strong lath martensite matrix, fine precipitates of particular species for strengthening, adequate $\mathrm{Cr}$ concentration in the matrix for corrosion resistance and controlled amounts of undesirable phases throughout the entire heat treatment. Two alloys utilizing $\mathrm{MC}$ carbides and $\mathrm{Ni}_{3} \mathrm{Ti}$ intermetallics, respectively, are designed employing the genetic approach. For the alloys designed, the cost effects of each single element are investigated and both the most and the least cost effective elements are identified. Subsequently the alloy design model was extended to take into account alloying costs by employing the ratio of strengthening contribution to alloying costs as the new optimization factor. Redesigned alloys display significant cost reductions without significantly sacrificing the strength. The extended model is shown to provide valuable guidelines in the industrial practice to design/modify alloy compositions, and optimize strength and cost in an integrated manner.
\end{abstract}

KEY WORDS: alloy design; high strength steels; cost; precipitation; carbide; intermetallics; thermodynamics; genetic algorithm.

\section{Introduction}

Steels combining valuable properties such as an ultrahigh-strength (UHS), a good ductility and corrosion resistance will always be required for demanding industrial and military applications. Such high-end UHS stainless steels possess a large number of alloying elements such as $\mathrm{C}, \mathrm{Cr}$, $\mathrm{Ni}, \mathrm{Al}, \mathrm{Ti}, \mathrm{Mo}, \mathrm{V}, \mathrm{Mn}, \mathrm{Nb}, \mathrm{Co}, \mathrm{Cu}, \mathrm{W}, \mathrm{Si}, \mathrm{B}$ and $\mathrm{N}$ in wide but controlled ranges of concentrations. The alloying elements play various metallurgical roles, e.g. solid solution strengthening, hardenablity enhancement, grain refinement, precipitation promoter of various species, and stabilizer of specific phases etc. Owing to complex interactions among different alloying elements, the conventional empirical alloy design/optimization methodology is no longer sufficient. Hence, computational guided alloy design of various types, such as thermodynamics-aided design, ${ }^{1-4)}$ artificial neural networks ${ }^{3,5,6)}$ and ab initio models ${ }^{7,8)}$ are being used increasingly.

New alloys not only require good mechanical and corrosion resistant properties, and also the cost price is of prime importance. It is well known that certain elements are considerably more expensive than others, while contributing to the properties to a comparable degree. For instance, if strength is to be realized via precipitation strengthening, $\mathrm{V}$ and $\mathrm{Nb}$ can be replaced by $\mathrm{Ti}$ due to the relatively lower price, while keeping the same level of MX carbides strengthening contribution. However, such substitutions are not straightforward if other effects and interactions among alloying elements are to be taken into account. Therefore, incessant efforts have been taken throughout the development of steels, both by industries and academies, to modify steel with leaner chemistry ${ }^{9-13)}$ and/or more economical process routes. ${ }^{14,15)}$ Nevertheless, competing and/or conflicting alloying effects on alloy cost versus alloy properties, make the empirical alloy design approach even more inefficient and hence a system optimization of the performance/price ratio in alloy design become an even more attractive target. There are very few attempts to deal with this problem in a systematic way. A very recent investigation ${ }^{16)}$ revealed such a trade-off among properties of creep resistance, density and alloying cost etc, in the design of nickel-based single crystal superalloys.

Recently, a theory-guided computational alloy design model for new UHS stainless steel grades has been presented by Xu et al., ${ }^{17-20)}$ in which alloy compositions and heat treatment parameters (austenitization and ageing temperatures) are simultaneously optimized applying genetic algorithm, so as to obtain desirable microstructure components and avoid undesirable phase considering the entire heat treatment process. The model was successfully applied to the design of UHS stainless steels using one or several types of precipitates, $\mathrm{MC}$ carbides, $\mathrm{Cu}$ clusters and $\mathrm{Ni}_{3} \mathrm{Ti} / \mathrm{NiAl}$, as the main strengthening factor. Characterizations of prototype alloys 
based on these model optimizations confirmed the presences of the intended precipitates, as well as very high mechanical and corrosion resistant properties comparable to those of industrial grades with a long optimization history. ${ }^{21,22)}$ In the present work, the model is extended to explore alloying cost effects: the first step is to investigate cost effects of each element for the previously designed alloys; the second step is to introduce the performance-cost ratio as the optimization parameter and to completely redesign the alloy.

\section{Model Development}

The combination of UHS and good toughness can be realized via a uniform dispersion of fine precipitates in a lath martensite matrix. This microstructure is obtained via a twostep heat treatment: firstly solution treatment followed by quench and secondly ageing treatment for precipitation. The solution treatment is aimed to achieve a homogenous and fully austenitic state and hence to obtain a fully lath martensitic structure upon subsequent quenching process. The fully martensitic matrix can be further strengthened by an ageing treatment, which promotes the formation of desirable precipitates, e.g. MC carbide, $\mathrm{Cu}$ clusters and $\mathrm{Ni}_{3} \mathrm{Ti}$ intermetallics, with the desired dispersion of a dense network of nanosized particles. ${ }^{1,23-26)}$ Moreover, good corrosion resistance can be achieved by ensuring a sufficient $\mathrm{Cr}$ concentration in the matrix upon the completion of precipitation. Furthermore, while fostering the formation of desirable microstructures, the formation of phases limiting strength or toughness, e.g. $\delta$-ferrite and primary carbides during austenitization and $\mathrm{M}_{23} \mathrm{C}_{6}, \mathrm{M}_{6} \mathrm{C}$ and $\mathrm{M}_{7} \mathrm{C}_{3}$, cementite, $\mu$ and $\chi$ phases upon ageing, should be prevented. ${ }^{27)}$ During ageing of the martensite, some softening of the martensite matrix must take place because of the depletion of $\mathrm{C}$ and the partial recovery of the dislocations. ${ }^{28-31)}$ It is clear that the martensite softening and the precipitation strengthening are intrinsically coupled processes as they both rely on the same carbon atoms. Hence exact quantification of the respective contribution of each mechanism is very difficult, if not impossible, to make. In general, the hardness of martensite matrix is correlated with its carbon content, most convincingly to the level $\mathrm{C}^{1 / 2}{ }^{28)}$ Therefore, the depletion of $\mathrm{C}$ may lead to a significant martensite softening, but most notably for higher carbon levels. $^{28-30)}$ Samuel et al. $^{28)}$ demonstrated that in a $\mathrm{Fe}-0.5 \mathrm{C}-0.6 \mathrm{Mn}$ system, the matrix hardness decreases from $650 \mathrm{HV}$ (as virgin martensite), to $600 \mathrm{HV}$ for a low tempering temperature and to $420 \mathrm{HV}$ for a high tempering temperature. However, they also found that for low $\mathrm{C}$ systems (0.1-0.2 mass \% C), especially in combination with carbide formers such as $\mathrm{Ti}, \mathrm{V}$ and Mo, the softening is much smaller, and decreases only gradually upon extended ageing. In the steels under consideration in the present work, all having a low $\mathrm{C}$ content and a low ageing temperature unlikely to lead to precipitate coarsening, the precipitation strengthening contribution is at a much higher level than the martensite softening. The strong imbalance in softening and precipitation strengthening in these marageing steels leads to a significant and well documented overall nett strength increase upon ageing. Therefore, the martensite softening is not taken into account in the present study. This simplifying assumption leads to a slight overestimation of the strength increase to be realized at higher carbon concentrations, but does not invalidate the approach nor the conclusions reached.

In order to achieve the targeted microstructures described above, a computational alloy design model coupled with a genetic algorithm has been developed and published elsewhere. ${ }^{17-20)}$ The alloy composition and the austenitization and ageing temperatures are optimized simultaneously to achieve the maximum precipitation-strengthening contribution while fulfilling all go/no go criteria along the entire heat treatment. Following the algorithm shown in Fig. 1, each candidate solution is evaluated step by step. Each of the following go/no go criterion needs to be fulfilled before further assessments of strengthening contribution is made: (i) the key factor of martensitic transformation, the martensite start (Ms) temperature is enforced as a go/no go criterion of (1) Ms temperature being above $473 \mathrm{~K}^{32)}$ (ii) The thermodynamic calculation is performed at the austenitization temperature $\mathrm{T}_{\text {Aus }}$. Two go/no go criteria are imposed subsequently as (2) equilibrium austenite volume fraction larger than $99 \%$ and (3) the maximum level of primary carbides limited to $0.5 \%$ in volume. (iii) Thermodynamic equilibrium is calculated at the ageing temperature $\mathrm{T}_{\text {Age }}$, and two go/no go criteria are enforced: (4) the maximum allowed volume fraction for all unavoidable undesirable phases together was arbitrarily set at $1 \%$ and (5) a minimum of $12 \mathrm{mass} \% \mathrm{Cr}$ in the matrix upon completion of the precipitation reactions is required so as to form the Cr-rich corrosion resistant film. (iv) For candidate solutions which fulfill all go/no go criteria (1)-(5), the precipitation-strengthening contribution (STR) of desired species is calculated as $f_{v}{ }^{1 / 2} r^{-1 / 2}$, where $f_{v}$ is the equilibrium volume fraction of the precipitate at the aging temperature and $r$ is the critical precipitate nucleus size, which is inversely proportional to the thermodynamic driving force for the precipitation. This strengthening estimation is based on a mixture of shear and bypass precipitate strengthening mechanisms and was justified in an earlier work. ${ }^{18)}$ The evaluation of a single candidate solution as described above is embedded in a genetic optimization scheme in order to find the combined optimal alloy compo-

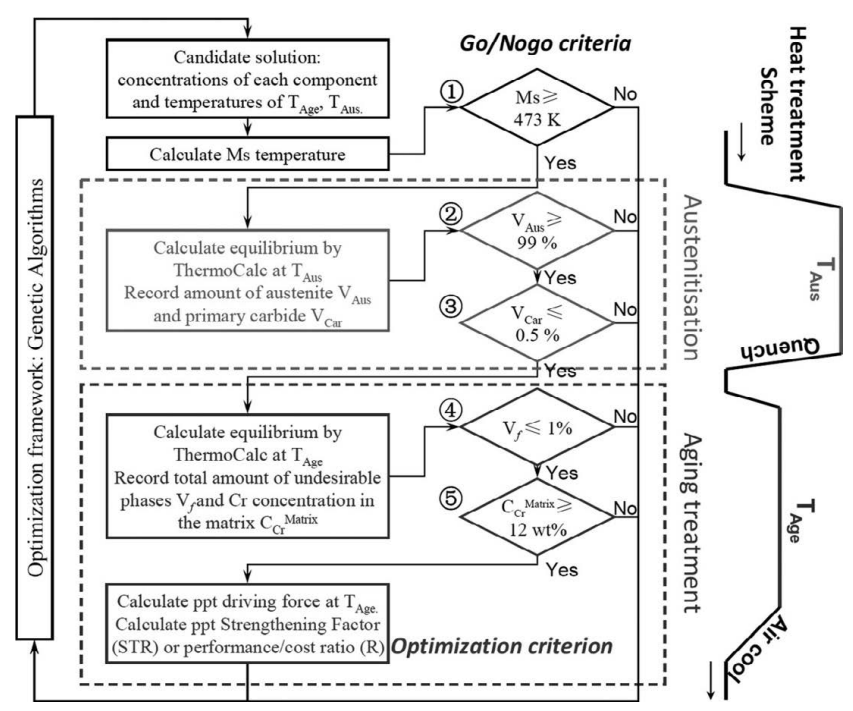

Fig. 1. Schematic diagram of the heat treatment scheme and algorithm of the thermodynamic calculation and criteria evaluation. 
sition and heat treatment temperatures in an effective manner. The model was shown to be able to justify the composition and heat treatment temperatures of existing UHS stainless steel grades. ${ }^{19)}$

As indicated in the introduction the optimization of the composition was made not taking into account the cost price of the alloying elements. The cost prices are subject to the movements of metal markets as well as the costs involved in mining and refining. The values expressed in arbitrary units (a.u.) used in our calculations are shown in Table 1 and are accurate as of the early part of 2009, but should be taken as indicative and illustrative for the model performance only. In the present model we assume that processing costs are identical for all alloys, i.e. that the product yield and processing costs are not affected by composition. In the new model, $\mathrm{R}$, the ratio of the precipitation strengthening contribution/total alloying cost, rather than the precipitation STRengthening contribution (STR), is taken as the optimization factor. A series of new alloys employing the same family of strengthening precipitates to achieve the best strengthening contribution while minimizing the alloy cost has been predicted.

\section{Model Application}

In our optimization model steel compositions containing up to 13 alloying elements $(\mathrm{C}, \mathrm{Cr}, \mathrm{Ni}, \mathrm{Ti}, \mathrm{Mo}, \mathrm{Al}, \mathrm{Cu}, \mathrm{Co}$, $\mathrm{Nb}, \mathrm{N}, \mathrm{V}, \mathrm{Mn}$ and $\mathrm{Si}$ ), greatly surpassing the range of interactions to be considered intuitively even by the most experienced alloy designer, were considered. The concentrations of all alloying elements were allowed to vary except for $\mathrm{Mn}$ (set at 0.5 mass\%) and $\mathrm{N}$ (set at 0.01 mass\%), as recommended for the facilitation of alloy production on the industrial scale. The candidate solution is represented in the genetic model as a chromosome which concatenates 11 variable concentrations together with the austenitization and ageing temperatures (i.e. 13 genes), allowing for the simultaneous optimization of alloy composition, austenitization and ageing temperatures. Thermodynamic calculations were performed by ThermoCalc coupled with the TCFE6 database and a tailored database for $\mathrm{Ni} / \mathrm{Ti}$-based precipitates. The concentrations and temperatures were varied within ranges based on financial and technological constraints (Table 1). Each component was allowed to take 32 potential

Table 1. Costs of alloying elements, concentration and temperature ranges applied in the calculation. Concentrations are in weight percent, temperatures are in $\mathrm{K}$ and alloying costs are in Euro per 0.1 mass $\%$.

\begin{tabular}{lcrrrrrrr}
\hline & $\mathrm{C}$ & \multicolumn{1}{c}{$\mathrm{Cr}$} & \multicolumn{1}{c}{$\mathrm{Ni}$} & $\mathrm{Ti}$ & \multicolumn{1}{c}{$\mathrm{Mo}$} & \multicolumn{1}{c}{$\mathrm{Al}$} & $\mathrm{Cu}$ & \multicolumn{1}{c}{$\mathrm{Co}$} \\
\hline Cost & - & 2.79 & 12.60 & 3.14 & 23.33 & - & 4.50 & 35.23 \\
Min & 0.01 & 12.00 & 1.00 & 0.01 & 0.50 & 0.01 & 0.50 & 0.01 \\
Max & 0.30 & 20.00 & 15.00 & 2.00 & 10.00 & 2.00 & 2.00 & 2.00
\end{tabular}

\begin{tabular}{ccccccccc}
\hline & $\mathrm{Nb}$ & $\mathrm{N}$ & $\mathrm{V}$ & $\mathrm{Mn}$ & $\mathrm{Si}$ & $\mathrm{Fe}$ & $\mathrm{T}_{\text {Age }}$ & $\mathrm{T}_{\text {Aus }}$ \\
\hline Cost & 29.09 & - & 34.38 & 0.75 & 1.27 & - & - & - \\
Min & 0.01 & 0.01 & 0.01 & 0.50 & 0.30 & Bal. & 693 & 1223 \\
$\operatorname{Max}$ & 1.00 & 0.01 & 1.00 & 0.50 & 1.00 & Bal. & 848 & 1533 \\
\hline
\end{tabular}

concentrations by dividing its compositional range equally. The ageing temperature and austenitization temperature were allowed to vary within the range of 693-848 and $1223-1533 \mathrm{~K}$ with intervals of 5 and $10 \mathrm{~K}$, respectively.

The original model has been applied to design alloys strengthened by $\mathrm{MC}$ carbides and $\mathrm{Ni}_{3} \mathrm{Ti}$ precipitates, termed alloy $\operatorname{Car}(\mathrm{x})$ and NiTi(x), respectively. Two series of alloys were computationally designed: Alloy Car2 and NiTi2 were designed to optimize the strengthening contribution (STR) of the intended species without considering cost effects, while alloy Car3 and NiTi3 were optimized with the modified model to achieve the best performance-cost ratio $\mathrm{R}$. The optimal compositions with corresponding temperatures are shown in Table 2. It should be mentioned that, although the alloys were designed to maximize the precipitation strengthening contribution of one particular precipitate only, i.e. $\mathrm{MC}$ carbide or $\mathrm{Ni}_{3} \mathrm{Ti}$ intermetallics, the thermodynamic calculations for the optimal compositions predicts that both grades possess multiple precipitates, i.e. combination of MX carbides, $\mathrm{Cu}$ clusters and $\mathrm{Ni}_{3} \mathrm{Ti}$ intermetallics.

\section{Results and Discussions}

\subsection{Cost Effects of Each Single Component}

Alloys Car2 and NiTi2 are taken as baselines to explore cost effects of each component and to demonstrate effects of composition in relation to cost as well as to the precipitation strengthening contribution. To this aim the compositional domains explored are extended beyond the ranges shown in Table 1: from an approximately zero concentration up to three times the maximum shown there. The total extra alloying cost of each composition is calculated according to Table 1 and the strengthening contribution is estimated at the optimal austenitization and ageing temperature as shown in Table 2. Those compositions which do not fulfill all go/ nogo criteria are not considered as valid solutions. The correlation of extra alloying cost and precipitation strengthening contribution, both of which are functions of concentrations, is shown in Figs. 2 and $\mathbf{3}$ for alloy Car2 and NiTi2 respectively. Each symbol represents one particular element. The closed symbols represent concentrations within the design window (Table 1) and open symbols correspond to extended concentrations either below minimal or up to three

Table 2. Compositions of alloy Car2, Car3, NiTi2 and NiTi3. Compositions are in weight percent.

\begin{tabular}{lcccccccc}
\hline & $\mathrm{C}$ & $\mathrm{Cr}$ & $\mathrm{Ni}$ & $\mathrm{Ti}$ & $\mathrm{Mo}$ & $\mathrm{Al}$ & $\mathrm{Cu}$ & $\mathrm{Co}$ \\
\hline Car2 & 0.075 & 12.00 & 4.16 & 0.46 & 0.50 & 0.01 & 2.00 & 2.00 \\
Car3 & 0.075 & 12.00 & 1.90 & 0.33 & 0.50 & 0.01 & 0.50 & 0.01 \\
NiTi2 & 0.010 & 12.00 & 13.19 & 2.00 & 0.50 & 1.42 & 0.50 & 1.55 \\
NiTi3 & 0.010 & 12.00 & 10.94 & 2.00 & 0.50 & 1.17 & 0.69 & 0.01
\end{tabular}

\begin{tabular}{ccccccccc}
\hline & $\mathrm{Nb}$ & $\mathrm{N}$ & $\mathrm{V}$ & $\mathrm{Mn}$ & $\mathrm{Si}$ & $\mathrm{T}_{\text {Age }}$ & $\mathrm{T}_{\text {Aus }}$ & $\mathrm{Fe}$ \\
\hline Car2 & 0.11 & 0.01 & 0.01 & 0.50 & 0.55 & 738 & 1533 & Bal \\
Car3 & 0.01 & 0.01 & 0.01 & 0.50 & 0.30 & 718 & 1383 & Bal \\
NiTi2 & 0.01 & 0.01 & 0.49 & 0.50 & 0.30 & 758 & 1403 & Bal \\
NiTi3 & 0.01 & 0.01 & 0.01 & 0.50 & 0.30 & 733 & 1323 & Bal \\
\hline
\end{tabular}




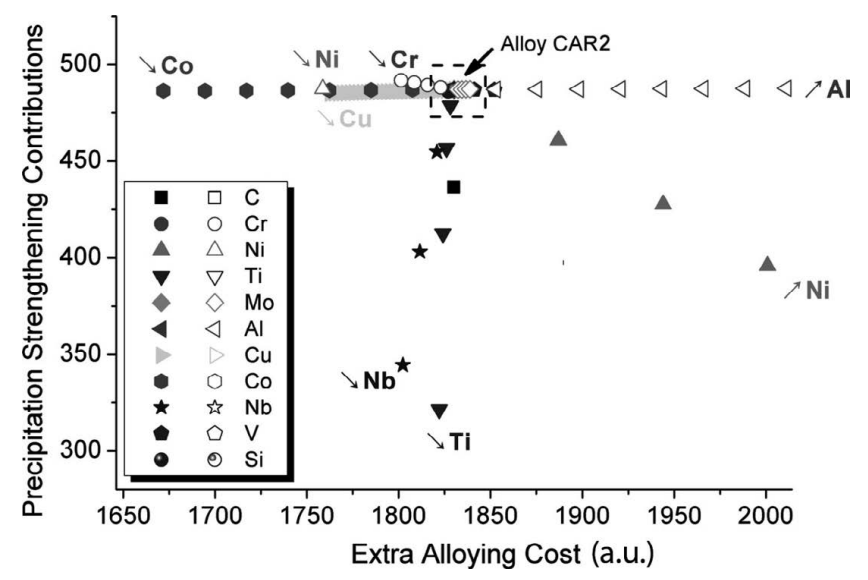

Fig. 2. Compositional effects of each alloy element on extra alloying cost and precipitation strengthening contribution. Analysis is performed based on alloy Car2 and only compositions fulfilling all go/nogo criteria are shown.

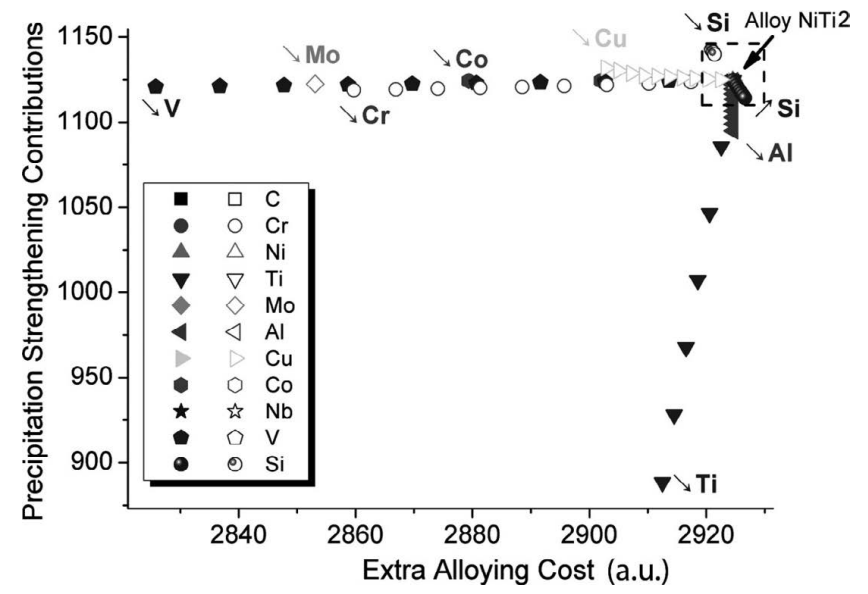

Fig. 3. Compositional effects of each alloy element on extra alloying cost and precipitation strengthening contribution. Analysis is performed based on alloy NiTi2 and only compositions fulfilling all go/nogo criteria are shown.

times of the maximal as shown in Table 1.

In Fig. 2, all points to the left of alloy Car2 correspond to concentration reductions and a reduction of the total alloying costs. From the figure it is obvious that both Ti and $\mathrm{Nb}$ are very cost effective for precipitation strengthening and their concentrations, especially of $\mathrm{Ti}$, should not be decreased. This observation applies to alloy Car2 especially because it utilizes $\mathrm{Ti} / \mathrm{NbC}$ as the dominant strengthening precipitate family. On the other hand, reductions of $\mathrm{Ni}, \mathrm{Cu}$ and especially Co will clearly reduce the total extra alloying cost without sacrificing the precipitation strengthening contribution. The analysis also shows that if the lower limit of $\mathrm{Cr}$ concentration is reduced to $11 \mathrm{mass} \%$, the alloying cost drop considerably but the precipitate strengthening effect is increased while all other go/nogo criteria, including the minimum $\mathrm{Cr}$ level, are met. Figure 2 also shows that increasing the Ni concentration will yield higher cost without gaining a significant benefit in strength. Further increase of Ni concentration will stabilize the austenite and result in an Ms temperature lower than $473 \mathrm{~K}$ and hence is not a valid solution and not presented in the plot. Increasing the Al level will slightly increase the strengthening but is not cost effec-

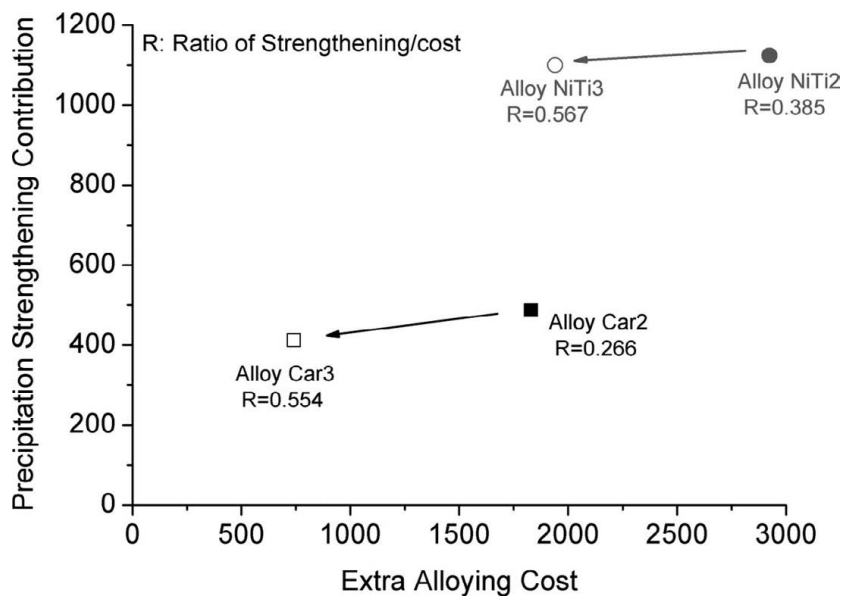

Fig. 4. Comparison of extra alloy cost v.s. precipitation strengthening contribution of the first alloy series (Alloy Car2 and Car3) and the second series (Alloy Car3 and NiTi3).

tive. For alloying elements other than those discussed above, their contribution to strength or cost is small or their approved concentration windows is thus narrow, that one or more of go/nogo criteria are no longer fulfilled. The best solution resulting from Fig. 2 is to reduce the Co concentration from 0.020 to 0.016 mass $\%$, which results in a reduction of alloying cost from 1830 to 1670 without sacrificing a notable amount of strength. A combination of adjustment of concentration levels of multiple components may lead to an even better compromise but this is outside a simple single component cost effect analysis.

A similar analysis was applied to alloy NiTi2. Figure 3 indicates that $\mathrm{Ti}$ is the most cost effective strengthening element in NiTi2 as well, which is to be expected as $\mathrm{Ni}_{3} \mathrm{Ti}$ was the intended to be the principal strengthening precipitates in this alloy. However, the other component of $\mathrm{Ni}_{3} \mathrm{Ti}$ intermetallics, $\mathrm{Ni}$, displays a narrow allowed concentration window and no cost effects can be discovered. If the Ni concentration drops far below the current value, it will stabilize undesirable phases and if its concentration increases, the Ms temperature will decrease and hence the $\mathrm{Ms}>473 \mathrm{~K}$ criterion can not be fulfilled. Moreover, Fig. 3 shows that, V and Co levels are a bit overdone in this alloy as the strength does not drop noticeable if the concentration level is dropped, but the alloying cost would drop substantially. Figure 3 also suggests that, lower limits of $\mathrm{Mo}, \mathrm{Cr}, \mathrm{Cu}$ and $\mathrm{Si}$ can be applied as the strengthening effect will keep more or less the same level. In the case of $\mathrm{Cu}$ and $\mathrm{Si}$, a reduction in concentration even increases the strengthening contribution slightly. As the global optimum composition was found via the genetic algorithm, there are no compositions which would reach a higher strengthening level within the search domain, regardless of alloying cost.

\subsection{Cross Effects of Alloying Cost: Alloy Redesign Employing $R$ as the Optimization Parameter}

As introduced in section 2, the ratio of precipitation strengthening contribution to total extra alloying cost, $R$, is employed as the optimization factor in the design of new alloys Car3 and NiTi3. Figure 4 shows, in a performancecost diagram, relative positions of the alloys designed with and without considering cost effects. For alloys employing 
$\mathrm{Ni}_{3} \mathrm{Ti}$ as strengthening phases, applying $\mathrm{R}$ as the optimization factor results in alloy NiTi3, which has a $2 \%$ lower precipitation strengthening contribution but a 33\% lower alloying element cost. The ratio $\mathrm{R}$ increases from 0.385 to 0.567 . In the case of $\mathrm{MC}$ carbide strengthening, the strengthening contribution drops by $15 \%$ in alloy Car3, but more significantly, a cost reduction of nearly $60 \%$ is achieved! The performance/cost ratio increases from 0.266 to no less than 0.554 , which is a relative increase of over $100 \%$. The results of the new model demonstrate very clearly that by applying the performance/cost ratio as the optimization factor, a much better compromise can be obtained. Comparison between compositions of NiTi2 and NiTi3 in Table 2 reveals that such achievement is realized by reducing concentrations of $\mathrm{Ni}, \mathrm{Co}, \mathrm{V}$ and $\mathrm{Al}$ simultaneously while slightly increasing the $\mathrm{Cu}$ content. For alloy $\mathrm{Car} 3$, combining reductions of $\mathrm{Ni}, \mathrm{Ti}, \mathrm{Cu}, \mathrm{Co}, \mathrm{Nb}$ and $\mathrm{Si}$ levels yields a significant cost reduction. Nevertheless, the concentration of alloying elements required for strengthening mechanism, i.e. Ti in alloy $\mathrm{Car} 3$ and $\mathrm{Ni} / \mathrm{Ti}$ in alloy $\mathrm{NiTi3}$ remains at a high level in order to form corresponding precipitates. It is also interesting to discover that, in Table 2, both alloys Car3 and NiTi3 require lower austenitization and tempering temperature as compared to alloys Car2 and NiTi2, which may imply another industrial cost saving factor.

\subsection{Comparison to Existing Commercial Alloys}

To reveal the correlation of alloying cost and performance (precipitation strengthening contribution) of various commercial grades, strength increases after ageing treatment of different commercial UHS stainless grades are plotted in Fig. 5 as functions of their corresponding extra alloying costs calculated using the cost factors as defined in Table 1. It should be noticed that the strength increase after ageing treatment is not fully equivalent to precipitation strengthening contribution. The difference of matrix (lath martensite size, morphology and orientation), the state of strengthening solutes (concentration and distribution) and the nature of precipitates and their distribution all together determine the precipitation strengthening contribution. Mechanisms other than precipitation strengthening can also influence signifi-

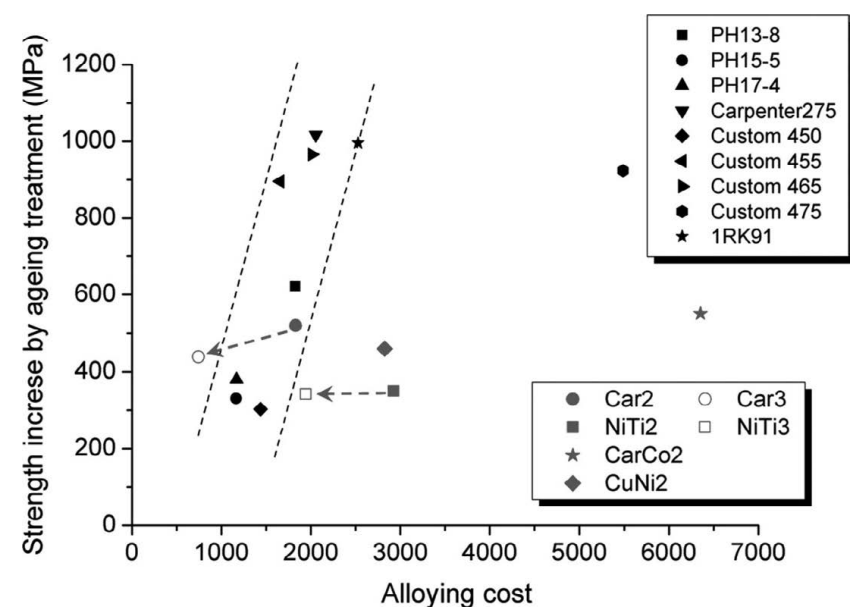

Fig. 5. Comparison of alloying cost vs. ageing strengthening of various commercial UHS stainless steels and designed alloys. cantly the strength changes after the ageing treatment. Therefore, strength increases as shown in Fig. 5 are just for indicative purpose. Nevertheless, interestingly, all commercial alloys lie in a linear band, which reveal a logical correlation: grades of higher strength level require more alloying and hence are more expensive.

In addition to commercial grades, experimental results of four prototype alloys designed without considering alloying cost, i.e., alloy $\mathrm{Car} 2, \mathrm{NiTi} 2, \mathrm{CarCo} 2$ and $\mathrm{CuNi} 2$, are also plotted in Fig. 5. It can be observed that those alloys are not cost effective as they fall to the right of the band, with the exception of alloy Car2. This can be explained as consequences of alloying strengthening mechanisms: NiTi2 and $\mathrm{CuNi} 2$ require significant amounts of $\mathrm{Ni}$ for strengthening and $\mathrm{CarCo} 2$ needs very expensive $\mathrm{Co}$, but Car2 utilizes relatively cheap $\mathrm{Ti}$ as the main alloying component. Moreover, expected strength increases of alloy Car3 and NiTi3, after ageing treatment, are calculated based on results of prototype alloy Car2 and NiTi2, and extrapolated proportionally to the relation shown in Fig. 4. It is clear that the performance/cost ratio significantly increases and alloy Car3 even goes to the left of the existing band, which suggests that alloy Car3 has very high potential of a cost effective high performance alloy.

\section{Conclusions}

The genetic alloy design approach based on thermodynamic principles presented elsewhere has been developed further to take into account alloying cost effects by introducing the new optimization factor $\mathrm{R}$, being the ratio of precipitation strengthening contribution to the total alloying cost, while all go/nogo criteria are still enforced so that alloy composition as well as the austenitization and ageing temperature are optimized to obtain tailored microstructure and undesirable phases are avoided. Two series of alloys utilizing $\mathrm{MC}$ carbides and $\mathrm{Ni}_{3} \mathrm{Ti}$ precipitates as strengthening phases respectively are designed: Alloys Car2 and NiTi2 without considering cost effects and Car3 and NiTi3 taking into account the cost consideration. The single element cost analysis based on alloy Car2 suggests that $\mathrm{Nb}$ and $\mathrm{Ti}$ are the most cost effective strengthening elements and $\mathrm{Co}, \mathrm{Ni}, \mathrm{Cu}$ and $\mathrm{Cr}$ can be reduced without sacrificing the strength. With alloy NiTi2, $\mathrm{Ti}$ is found to be the best strengthening element while decreases of $\mathrm{V}, \mathrm{Mo}, \mathrm{Cr}, \mathrm{Co}$ and $\mathrm{Cu}$ concentration can significantly limit the alloy cost whilst preserving the high strength level. Alloys Car3 and NITi3 redesigned employing $\mathrm{R}$ as optimization factor display significant improvements of the performance-cost ratio, by $108 \%$ and $47 \%$ respectively. Moreover, verification of the model with various commercial alloys and designed alloys suggests that alloys designed without considering cost effects are not cost effective as compared to commercial grades while alloys Car3 and NiTi3 show significant improvement, especially alloy Car3 being superior to existing commercial counterparts.

\section{REFERENCES}

1) C. E. Campbell and G. B. Olson: J. Comput.-Aided Mater. Des., 7 (2000), 145.

2) V. Trabadelo, S. Giménez, T. Gómez-Acebo and I. Iturriza: Scr. Mater., 53 (2005), 287.

3) F. Brun, T. Yoshida, J. D. Robson, V. Narayan, H. K. D. H. 
Bhadeshia and D. J. C. MacKay: Mater. Sci. Technol., 15 (1999), 547.

4) A. A. Howe and D. C. J. Farrugia: Mater. Sci. Technol., 15 (1999), 15 .

5) H. K. D. H. Bhadeshia: ISIJ Int., 39 (1999), 966

6) S. Datta, F. Pettersson, S. Ganguly, H. Saxén and N. Chakraborti: ISIJ Int., 47 (2007), 1195.

7) S. Hao, W. K. Liu, B. Moran, F. Vernerey and G. B. Olson: Comput. Meth. Appl. Mech. Eng., 193 (2004), 1865.

8) L. Vitos, P. A. Korzhavyi and B. Johansson: Nat. Mater., 2 (2003), 25.

9) H. Tamehiro, M. Murata, R. Habu and M. Nagumo: Trans. Iron Steel Inst. Jpn., 27 (1987), 120.

10) M. Hillert, K. Nilsson and L. E. Toerndahl: J. Iron Steel Inst., 209 (1971), 49.

11) A. J. Sedriks: Corros., 42 (1986), 376

12) U. Brux, G. Frommeyer and J. Jimenez: Steel Res. Int., 73 (2002), 543.

13) Traint, A. Pichler, K. Hauzenberger, P. Stiaszny and E. Werner: Steel Res. Int., 73 (2002), 259.

14) R. Lagneborg: Scand. J. Metall., 26 (1997), 255.

$15)$ B. K. Panigrahi: Bull. Mater. Sci., 24 (2001), 361.

16) R. C. Reed, T. Tao and N. Warnken: Acta Mater., 57 (2009), 5898

17) W. $\mathrm{Xu}, \mathrm{P}$. E. J. Rivera-Diaz-del-Castillo and S. van der Zwaag: Comput. Mater. Sci., 44 (2008), 678.

18) W. Xu, P. E. J. Rivera-Diaz-Del-Castillo and S. Van Der Zwaag:
Philos. Mag., 88 (2008), 1825.

19) W. Xu, P. E. J. R. D. d. Castillo and S. v. d. Zwaag: Comput. Mater. Sci., 45 (2009), 467.

20) W. Xu, P. E. J. Rivera-Diaz-Del-Castillo and S. Van Der Zwaag: Philos. Mag., 89 (2009), 1647

21) W. Xu, P. E. J. Rivera-Diaz-del-Castillo, W. Wang, K. Yang, V. Bliznuk, L. A. I. Kestens and S. van der Zwaag: Acta Mater., 58 (2010), 3582.

22) W. Xu, P. E. J. Rivera-Díaz-del-Castillo, W. Yan, K. Yang, D. San Martín, L. A. I. Kestens and S. van der Zwaag: Acta Mater., 58 (2010), 4067.

23) C. Servant, E. H. Gherbi and G. Cizeron: J. Mater. Sci., 22 (1987), 2297.

24) D. H. Ping, M. Ohnuma, Y. Hirakawa, Y. Kadoya and K. Hono: Mater. Sci. Eng. A, 394 (2005), 285.

25) K. Stiller, M. Hattestrand and F. Danoix: Acta Mater., 46 (1998), 6063.

26) D. Raabe, D. Ponge, O. Dmitrieva and B. Sander: Scr. Mater., 60 (2009), 1141.

27) A. F. Padilha and P. R. Rios: ISIJ Int., 42 (2002), 325.

28) F. H. Samuel and A. A. Hussein: Mater. Sci. Eng., 58 (1983), 113.

29) G. Kruss: Encyclopedia of Materials: Science and Technology, Elsevier, Oxford, (2001), 5193

30) T. Ohmura, T. Hara and K. Tsuzaki: Scr. Mater., 49 (2003), 1157.

$31)$ K. A. Taylor and M. Cohen: Prog. Mater. Sci., 36 (1992), 225.

32) K. Ishida: J. Alloy. Compd., 220 (1995), 126. 